\title{
Mobile Disaster Communication in Wireless Network Communication
}

\author{
V.Vennisa ${ }^{1}$, Dr.Ramkumar prabhu ${ }^{2}$ \\ ${ }^{1}$ UG Scholars, Department of ECE, Apollo Engineering College, Chennai. \\ ${ }^{2}$ Professor, Department of ECE, Apollo Engineering College, Chennai.
}

\begin{tabular}{lll}
\multicolumn{3}{l}{ Article Information } \\
Received & $:$ & 18 April 2020 \\
Revised & $:$ & 19 May 2020 \\
Accepted & $:$ & 28 May 2020 \\
Published & $:$ & 10 June 2020
\end{tabular}

Corresponding Author:

V.Vennisa

Email:Vennisav@gmail.com

\begin{abstract}
Recent day In disastrous rescue mission has many challenges to Establishing a short and temporary communication system to provision disaster based communications and networking. This research paper main goal is Propagation of communication emergency messages to neighbors or people is reflected to deliver more prompt assistance than remote or distant rescue entities. The emergency communication service in order to improve communication range, victim localization and evacuation route planning. Since, the popularity of smart phones has been unprecedentedly increased. Thus increases the possibilities of successful receiving and recognizing SOS messages. SOS messages are generated by a code called as MORSE code. This research focus on to maintain and establish communication in situation of an disaster communication among a smartphone as a source and destination node like base station in case of absence. This communication has followed as one way communication from source to any destination inside an emergency region. To achieve this prime goal of this research is to take improvement of wireless communication of smartphones to establish and broadcast and forward the message from the source to rescue unit. In this case, to generating and establishing new communication client or victims and outside world, sending the emergency messages done over the wireless technology. Reestablishment of communication has in our prototype. This research has considered application, no hypothesis is made with respect to the reality of a complete and whole communication link among two commination nodes wishing to participate to communicate. Any possible node can opportunistically be used as a next hop, provided takes the message closer to the exact final destination. These features match the perception of opportunistic networking.
\end{abstract}

Keywords: Location identification, SOS messages, smart phones, search and rescue, wireless networks.

Copyright (c) 2020: V.Vennisa. This is an open access distribution, and reproduction in any medium, provided Access article distributed under the Creative Commons Attribution License the original work is properly cited License, which permits unrestricted use.

Citation: V.Vennisa, Dr.RamkumarPrabhu "Mobile Disaster Communication in Wireless Network n Communication, "Journal of Science, Computing and Engineering Research, 1(2), 31-35, May-June 2020.

\section{INTRODUCTION}

At the point when blasted by a disastrous catastrophic event, crisis salvage activity is exceptionally basic to numerous lives. Numerous individuals caught in the grievous regions under fallen structures or avalanches may have a huge opportunity to endure on the off chance that they protected in "Golden 72 Hours". Individuals cleared since their home stuck in expressways or done havens necessity to convey to one another for different explanation. In any case, Communication systems were generally down because of different reasons. Loss of Communication structures thru the salvage activity very troublesome. Along these lines, a crisis Communication system must be executed.

The crisis Communications system frameworks are normally equipped for both transmitting and getting data between numerous gatherings. These systems are regularly comprised of both input device components, sensors, yield specialized device components. The beginning of data can happen from different of sources and different areas, from which the system framework will propagate that data to at least one specific client.

\section{RELATED WORKS}

Because of the basic requirement for spare communiqué, moment help, and location identification in numerous applications, a few research ventures tended to this issue. A study with point by point grouping and correlation among the location identification algorithm dependent on the lognormal surveillance with exponential way misfortune model for wireless proliferation [1].This algorithm utilizes both the Received sign quality pointer of the Wi-Fi signals and the GPS area data of the rescuer's telephones to assess the areas of the sufferers [1]. The model can be utilized for both indoor and open-air conditions since it very well may be designed by comparing environmental characteristics [1]. Various detected mobile devices are intended to give a 
customized situational awareness, in this way further upgrading the adaptability and proficiency of salvage services [2]. It is accepted that the SOS cast application in a calamity situation cut off from conservative communiqué services, i.e., landline and cellular [3]. The cutting edge cellphone communiqué capacities to convey communications through a specially appointed system during a catastrophe, which reduces the customary cellular base station remote [4]. Communications created by the claim might comprise data around the time brand, telephone number (and much progressively close to home information), geographic information [4]. A MANET based spare communiqué and info scheme that can care an enormous number of salvage helpers. Accessible spare communiqué systems are Walkie-Talkie, spare mobile Communication, MANET based P2Pnet [5].

\section{A. Sos Message}

\section{PROPOSED SYSTEM}

In modern terminology, SOS is a "procedural signal" or "prosign" and the conventional method that compose a bar over the letters. In mainstream use, SOS became related to expressions such a "Save Our Soul", "Save Our Ship" and others. It is for the most part known by "Save Our Ship". The SOS message was created by "Morse code".

\section{B.Morse code}

Morse code is a Communication language made by Samuel Morse and Alfred Vail initially to be utilized with the message. It's a strategy utilized trendy telecommunication to encode text fonts as consistent arrangements of two diverse signal periods called dots and dashes and dahs. Morse code is the detailed system of dots, dashes and spaces used to represent numbers, accentuation, and letters of the letter set. It is utilized to shower as a code and an approach to convey without the capacity or necessity to utilize genuine appeals. SOS is the celebrated word in Morse code. In spite of prevalent thinking, SOS doesn't signify "Save Our Ship", in spite of the fact that it frequently did only that. Or maybe, it was picked as the global Morse Code trouble signal in light of the fact that the three dots for $\mathrm{S}$ and three dashes for $\mathrm{O}(\ldots--\ldots)$ make a clear and distinct signal. Our proposed system is an individual spare Communication service by integrating microcontrollers with Zigbee handsets so as to send an spare message from the victim side to nearby possible nodes.

We built up a calamity salvage application for setting up/scattering a crisis message. Here we will execute two nodes are impart each other utilizing Zigbee transceivers. We can send that data utilizing USB to RS232 converter fed into a smaller scale controller. Zigbee is utilized as an FM transceiver to transmit the spare message from the victim to nearby conceivable salvage units. The proposed system has the accompanying modules and highlights,

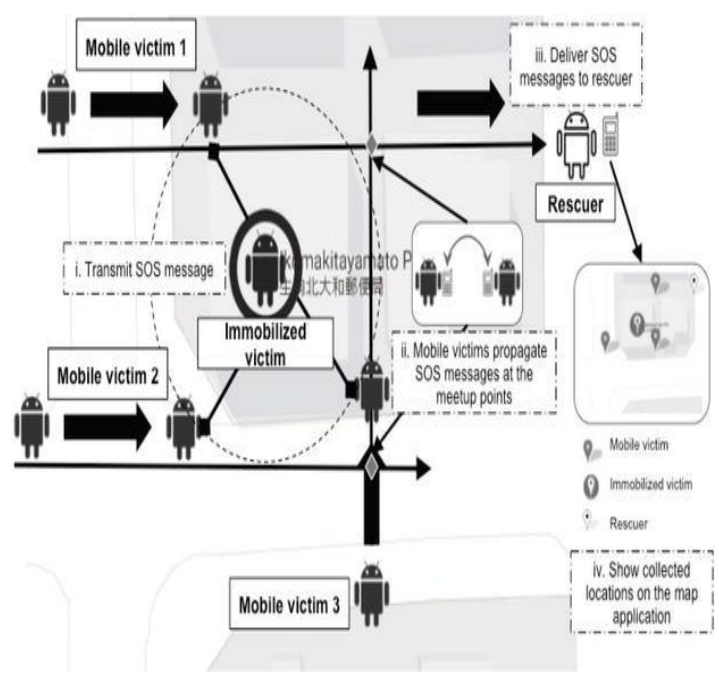

Figure 1 Proposed System

1. Registration module

2. SMS module

- send SOS

- send safe message

3. Victim person's identification

IV. RSEARCH DESIGN DIAGRAM

BLOCK DIAGRAM (TRANSMITTER SIDE-VICTIM SIDE)
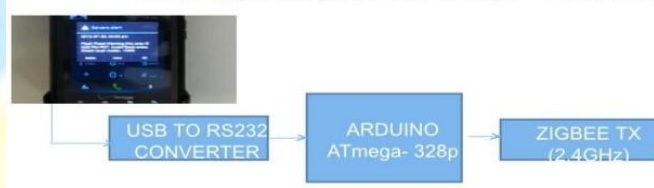

BLOCK DIAGRAM (RECEIVER RESCUE SIDE)

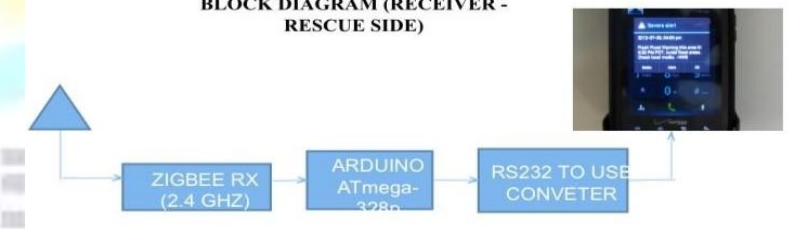

Figure 2 Block Diagram (Transmitter - Victim Side)

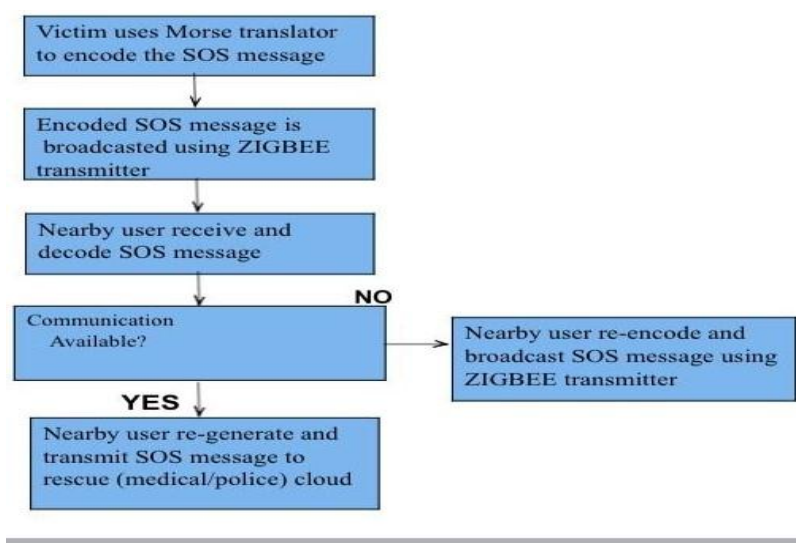

Figure 3 System Flow Diagram 


\section{A. Arduino ATmega 328p:}

Arduino is free-source hardware and software corporation, structure, client network that projects and produces single-board microcontrollers and microcontroller kits for constructing digital devices. This articles are authorized beneath the GNU Lesser General Public License (LGPL) or the GNU General Public License (GPL) [1] allowing production of Arduino boards and software circulation by anybody. Arduino boards are accessible monetarily in pre-assembled structure or as do-it-without anyone's help (DIY). Arduino logo Genuino Logo SVG Arduino Uno - R3.jpg Arduino Uno SMD R3Developer Arduino.cc produces many type of single-board microcontroller operating method none CPU Atmel AVR (8-bit), ARM cortex-M0+ (32-bit), ARM cortex-M3 (32bit), Intel quark (x86) (32-bit). Retention SRAM storage fash, EEPROM website www.arduino.cc Arduino panel schemes apply a collection of microprocessors and controllers.

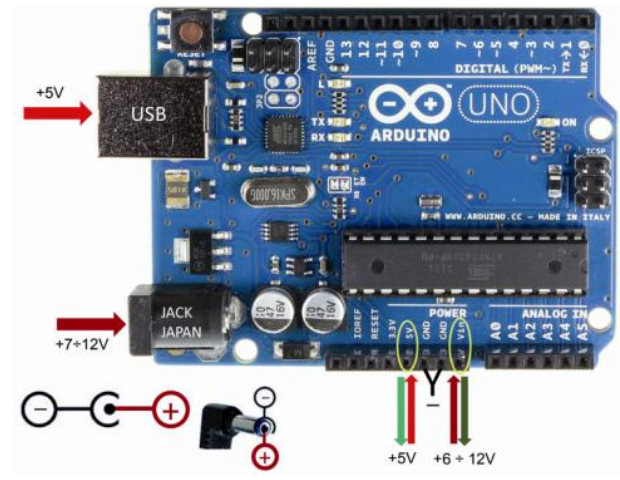

Figure 4 Arduino ATmega 328p model

1. Microcontroller: ATmega328P

2. Operating voltage: $5 \mathrm{~V}$

3. Input voltage: $7-12 \mathrm{~V}$

4. Flash memory: $32 \mathrm{~KB}$

5. SRAM: $2 \mathrm{~KB}$

6. EEPROM: $1 \mathrm{~KB}$

\section{B. Zigbee Module:}

ZigBee is an IEEE 802.15 .4 based specification is a setup of significant flat Communication protocols employed for wireless networking. It is a wireless novelty as an exposed global standard to report the remarkable desires of minimal effort, low-power wireless M2M networks. ZigBee $(\mathrm{CC} 2500)$ is a nominal effort open single-chip $2.4 \mathrm{GHz}$ handset projected for low power wireless applications. The RF transceiver is harmonized with a intensely configurable baseband modem.

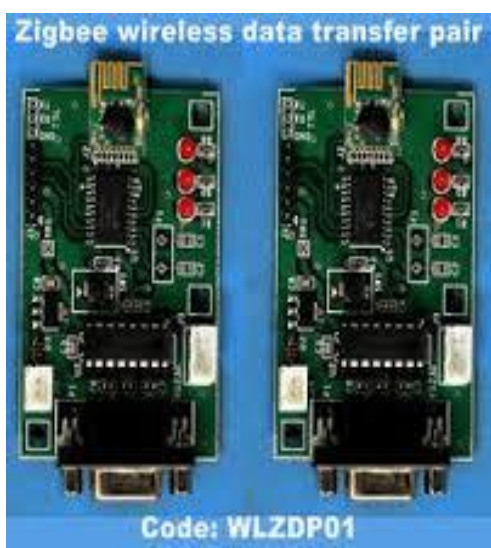

Figure 5 Zigbee Module

\section{USB-OTG Cable}

U052-06N-OTG-AM is a USB OTG (On-the-Go) cable that structures an exclusive USB Micro-B/USB combo connector with a coverable USB Micro-B assembled with the typical USB A-male connector. It goes about as an OTG cable with the coverable Micro-B connector pulled out, interfacing a USB device for example, a keyboard, mouse, or flash drive to an OTG compliant Micro-B device. Push the coverable USB Micro-B connector back in to utilize the cable as a standard USB 2.0 An/An expansion cable.

\section{SOFTWARE REQUIREMENTS}

\section{A. Embedded C}

Embedded $\mathrm{C}$ is a customary linguistic additions for $\mathrm{C}$ language encoding by the $\mathrm{C}$ standards commission to report mutual distinctive concerns that occur amid $\mathrm{C}$ extensions for several embeddedd systems. Embedded $\mathrm{C}$ encoding regularly needs custom-made extension lead to the $\mathrm{C}$ language so as to help improved microprocessor highlights, for example, fixed-point arithmetic, various memory panels, and essential I/O activities. In 2008, the $\mathrm{C}$ standards commission extended $\mathrm{C}$ language to report such abilities by giving a standard to all executions to grip fast to and it comprises many highpoints not reachable in ordinary $\mathrm{C}$, for example, fixed-point arithmetic, entitled report spaces, and essential I/O hardware addressing. Embedded C employs the better portion of the syntax and semantics of standard $\mathrm{C}$, e.g., main () function, mutable definition, data type affirmation, liable proclamations (if, switch case), circles (while, for), capacities, arrays and strings, assemblies and union, bit activities, macros, and so on.

Microprocessors-based systems; packages were shaped employing assemblers and joint to EPROMs. Nearby charity to be no mechanism to determine the program was doing. LEDs, switches, and so on were exploited to check for the correct implementation of the platform. However, they were excessively expensive and were not precisely consistent also. As time innovative, the operation of microprocessor- 
specific assembly-only as the programming language diminished, and embedded systems stimulated onto $\mathrm{C}$ as the embedded programming linguistic of choice. $\mathrm{C}$ is the greatest generally employed software design language for embedded workstations/controllers.

\section{B. Arduino Ide 1.8}

Integrated development environment (IDE) is a open, unified toolset for the extension of embedded submissions commissioning microchip's PIC and DSPIC microcontrollers. Arduino IDE 1.8.6 turns as a 32-bit application on MS Window, its relaxed to custom, and integrates a host of open-software constituents for quick solicitation improvements and super-charged troubleshooting. The free-source Arduino software (IDE) marks it modest toward comprise code and transmission it to the board. It runs on Windows, Mac OS X, and Linux. The location is written in Java and reliant on handling and other open-source software. This invention could be consumed with some Arduino board. It's integrated development environment (IDE) is a cross-stage solicitation (for Windows, macOS, Linux) that is inscribed in utilities from $\mathrm{C}$ and $\mathrm{C}++$. Its used to comprise and handover programs to Arduino well-matched boards, yet additionally, with the assistance of 3rd party cores, other trading development boards choice the columns icon from the MS word standard toolbar and subsequently choice the right number of segments from the selection palette.

\section{Proteus 8 Professional}

Designing PCBs are simple utilizing Proteus. We made our own plan or let Proteus fix that for us. Creation our specific scheme is simple, we simply place the segments utilized in the diagram and attraction traces over them. We likewise let Proteus accomplish the work. We put the segments in their respective places and select the "autoroute" choice. This will automatically draw different varieties of traces and chooses the best one. Around is additionally an "Auto placer" choice existing; this opportunity desires to stipulate the board dimensions by sketch the outline and size of the board so that, it can put the segments inside the board limits. In this way, we should simply make the schematic. This can be valuable for troubleshooting digital circuits.

We additionally simulated microcontrollers. The microcontrollers which can be simulated and incorporates PIC24, dsPIC33, 8051, Arduino, ARM7 based microcontrollers. The consumers can transfer the compilers for Proteus or utilize diverse compiler and dump the hex documents in the microcontroller in Proteus; and even associate continuously with the simulation utilizing switches, resistors, LDRs, and so forth. There are even virtual voltmeter, ammeter, oscilloscope, logic analyzer, etc

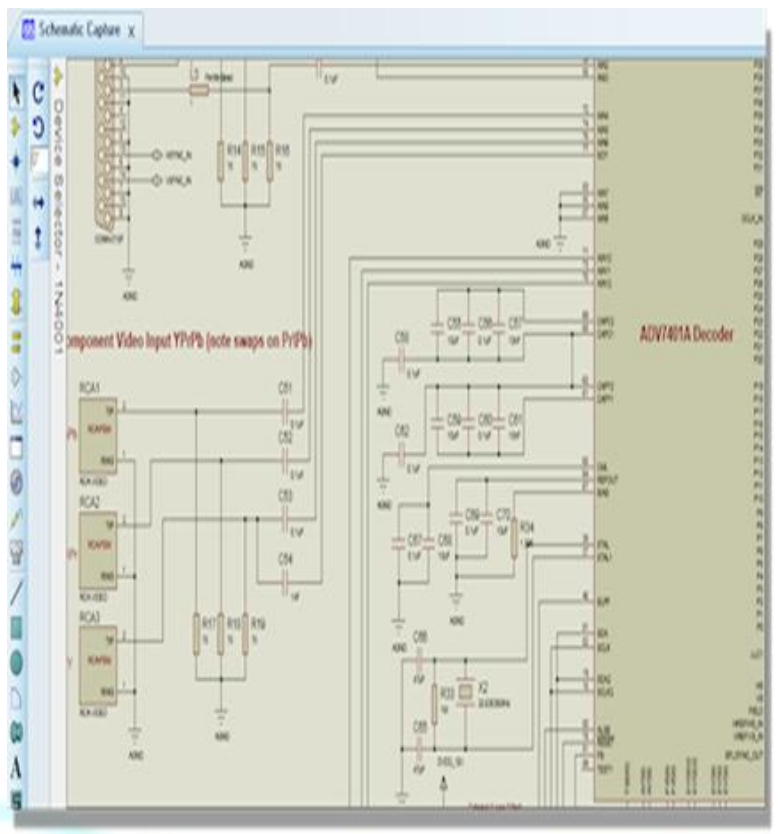

Figure 6 Proteus 8 design model

\section{Android Studio}

Android studio offers build form control tools, such as automation, dependency, management, and customizable could be retain your team in sync with build configurations. Current work projected and builds changes. Local and hosted libraries, and allowed us to tailor the build to de Une build variants that include your environment and run on a different code and assets, and continuous integration server relate diverse code reduction and such as Jenkins.

\section{E. Java Netbeans}

Net beans IDE agreement us promptly and efficiently form Java work region, mobile, and web presentations, just as HTML5 submissions with HTML, JavaScript, and CSS. IDE also contributes a strange planning of devices for PHP and $\mathrm{C} / \mathrm{C}++$ engineers. It's allowed and open-source and has an enormous network of consumers and engineers far and wide.

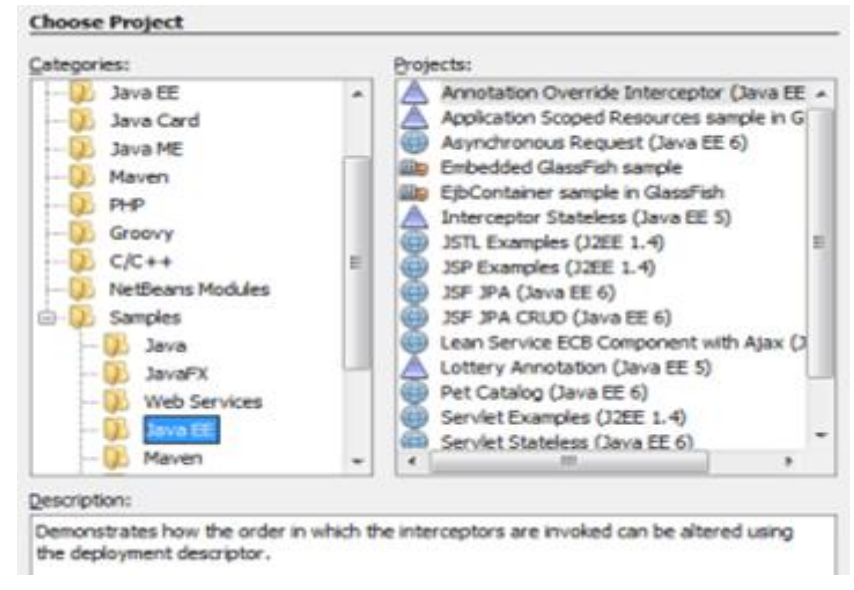

Figure 7 Java Beans Setup 
VII. HARDWARE SETUP AND OUTPUT

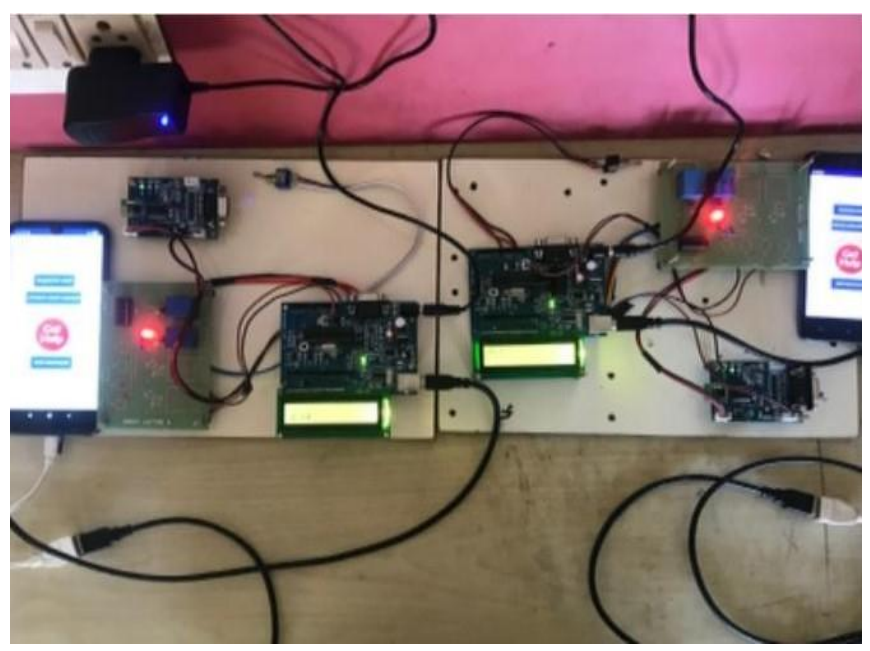

Figure 8 Hardware model

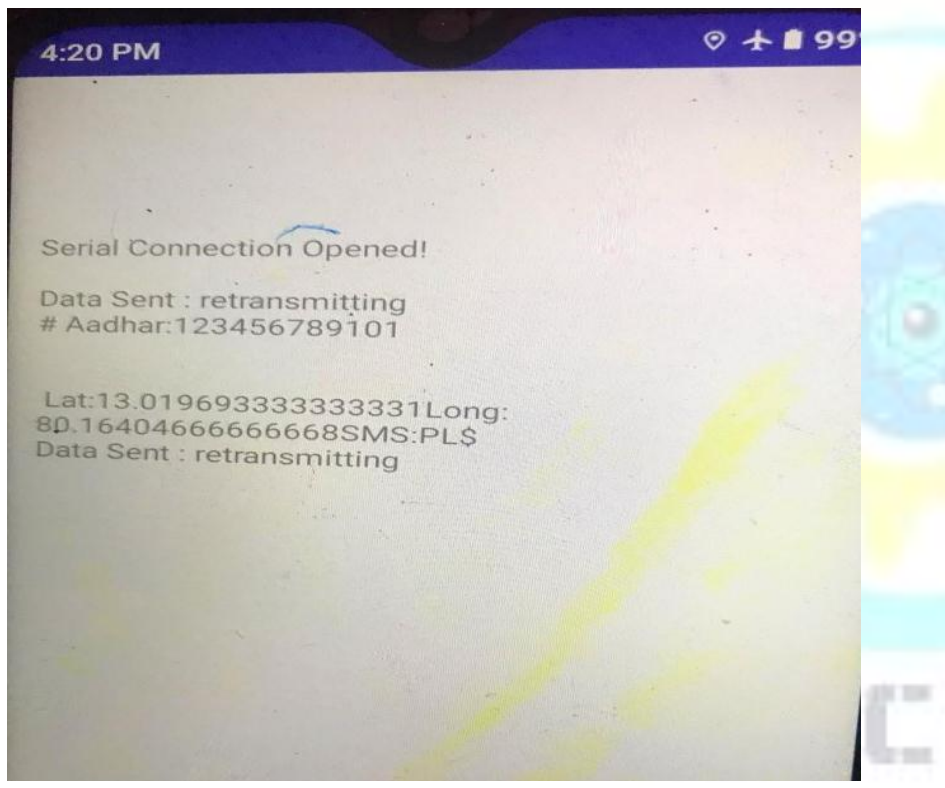

Figure 9 Experimental output

\section{CONCLUSION}

The most significant session we savvy from various occasions or fact that has shocking outcomes the mobile communiqué is essentially hampered and harm of communiqué method might be unpleasant results. This paper inspects the spare communique so as to opportune convey SOS message to protect experts in a fiasco period this can be set up by sending the spare message through wireless technology by utilizing Zigbee transceiver we can scatter the SOS message to close by potential nodes and this research created salvage app in which will get victim location (GPS) and spare message. The use of smartphones as message dispersing from the victim node to the salvage nodes does not rely upon any cellular network. Our debacle salvage App is valuable through normal threats, when base places are wrecked, execution the telephone clients unfit to call or direct an SMS to other people. Our system is conceivable that someone close to the individuals in an spare can give more moment help than a distant salvage group. This system can communicate messages in excess of 100 meters. Along these lines the victim can communicate the spare message to nearby individuals or salvage units.

\section{REFERENCES}

[1] Aisha Al-Sadi1, Hana' Al-Theiabat.,"Smartphone-Assisted Location Identification Algorithm for Search and Rescue Services",8th International Conference on Information and Communication Systems (ICICS), 2017.

[2] Yu-Jia Chen, Student Member, IEEE Chia-Yu Lin, Student Member, IEEE and Li-Chun Wang.,"Sensors-Assisted Rescue Service Architecture in Mobile Cloud Computing", IEEE Wireless Communications and Networking Conference,2014.

[3] Noriyuki Suzuki, Jane Louie Fresco Zamora, Shigeru Kashihara, Suguru., Yamaguchi "Location Estimation of Immobilized Persons through SOS Message Propagation”, 2012.

[4] Xian Wu, Maciej Mazurowski, Zhen Chen, Nirvana Meratnia., Spare Message Dissemination System for Smart phones During Natural Disasters", 11th International Conference on ITS TeleCommunications, 2011.

[5] Yao-Nan Lien, Hung-Chin Jang, and Tzu-Chieh Tsai.,A MANET Based Spare Communication and Information System for Catastrophic Natural Disasters”, ,2013.

[6] J. A. Besada, A. M. Bernardos, P. Tarrio, and J. R. Casar, "Analysis of tracking methods for wireless indoor localization," in Wireless Pervasive Computing, 2007. ISWPC '07.2nd International Symposium on, 2007.

[7] Kitasuka, T., K. Hisazumi, T. Nakanishi and A. Fukuda, "Positioning Techniques of Wireless LAN Terminals Using RSSI between Terminals", in Proceedings of the 2005 International Conference on Pervasive Systems and Computing (PSC-05), Las Vegas, Nevada, USA, 47-53,2005.

[8] W.C.Jakes, Microwave Mobile Communications, Wiley_Interscience, 1974.

[9] T. S. Rappaport, Wireless Communications Principles and Practice, New York: IEEE Press \& Prentice Hall PTR, 1996.

[10] "Castalia Wireless Sensor Netowrk Simulator - Home." [Online].Available:ttps://castalia.forge.nicta.com.au/index.php/en/. 2016.

[11] "OMNeT++ Discrete Event Simulator - Home." [Online]. Available: https://omnetpp.org/. 15-Dec-2016.

[12] C. Pu, "Evacuation Assisting Strategies in Vehicular Ad Hoc Networks," in IEEE Proc. UEMCON, November 2018.

[13] Ecuador Earthquake: Death Toll Jumps to 272; More Than2,500Injured,ttps://www.cnn.com/2016/04/17/americas/ecuad or-deadlyearthquake, Apr 18, 2016.

[14] H. Nishiyama, M. Ito, and N. Kato, "Relay-by-Smartphone: Realizing Multihop Device-to-Device Communications," IEEE Commun. Mag., vol. 52, no. 4, pp. 56-65, 2014.

[15] L. Bengtsson, X. Lu, A. Thorson, R. Garfield, and J. V. Schreeb, "Improved Response to Disasters and Outbreaks by Tracking Population Movements with Mobile Phone Network Data: A Post-Earthquake Geospatial Study in Haiti," PLoS medicine, vol. 8, no. 8, 2011. 